\title{
PROBLEM-BASED PROJECTS: A CATALYST FOR ENHANCING STUDENTS' SELF-DIRECTED LEARNING IN AN INFORMATION SECURITY COURSE
}

\author{
Marietjie Havenga ${ }^{1}$ and Lynette Drevin ${ }^{2}$ \\ ${ }^{1}$ Unit for Self-Directed Learning, North-West University, Potchefstroom, South Africa \\ ${ }^{2}$ School of Computer Science and Information Systems, North-West University, Potchefstroom, South Africa
}

\begin{abstract}
Although postgraduate students are required to be self-directed, this is not always the case. The aims of this study were twofold. Firstly, we investigated whether the use of problem-based projects supported students in implementing different cryptography algorithms as part of a group assignment. Secondly, we determined to which extent the use of problem-based projects enhanced students' self-directed learning. A qualitative methodology was followed. A cohort of 21 honours students enrolled for this elective course in Information Security. Students worked mainly in small groups of two on a project. Data collection involved completion of open-ended questions regarding information security and students' previous experiences in problem-based environments, completion of project sheets and narrative reflections regarding their project work. The data were manually coded to identify certain patterns of meaning. Results showed that problem-based projects provided opportunities for learning 'useful things in life' and strengthened team members' knowledge and skills. Problem-based projects served as a catalyst for enhancing students' self-directed learning in this Information Security course, which is beneficial for addressing real-life scenarios in the Information Technology profession. Additionally, an integrated model for self-directed learning skill development in a problem-based context was proposed.
\end{abstract}

\section{KEYWORDS}

Information Security Course, Problem-Based Project, Programming, Self-Directed Learning, Students

\section{INTRODUCTION}

Self-directed learning (SDL) comprises an educational space for the incremental development of lifelong and responsible learning where students need to take ownership of and manage their own learning processes (Knowles, 1975; UNESCO, 2015). This notion is emphasised as part of the mission statement of the university to "provide meaningful teaching and learning experiences and responsive and enabling environments ... so that its students can progressively become self-directed and lifelong learners who make distinctive contributions to society and the world of work" (North-West University Teaching and Learning Strategy, 2016:10). To instigate the development of SDL, several pedagogical approaches can be applied to prepare students for the development of employability skills. Problem-based learning (PBL) is acknowledged as a powerful student-centred strategy that provides the opportunity for authentic learning and enables students to develop professional skills (Mohd-Yusof, 2017). Ulseth and Guerra (2017) are of the opinion that various PBL approaches can be used for example, "problem-based, project organized learning" (Ulseth \& Guerra, 2017:vii). In this research, honours students developed problem-based projects in an Information Security course relating to cryptography algorithms. Honours students are selected for post-graduate studies according to their achievement in undergraduate courses. These students are expected to be driven by the desire to learn. Although it is expected from post-graduates to be able to manage their own learning processes, this is not always the case. In a study by Taylor and Goede (2012) regarding honours students' SDL readiness in a Data Warehousing course, they emphasise that lecturers need to assist students in developing a higher level of SDL to prepare them for careers in the IT environment. Consequently, the aims of this research were the following: we investigated whether the use of problem-based projects supported students in implementing different cryptography algorithms, and determined to which extent the use of 
problem-based projects enhanced students' self-directed learning. This paper is structured as follows: a literature overview is given and this is followed by the empirical research, the results and discussion, and the conclusion.

\section{LITERATURE OVERVIEW}

This section gives an overview regarding the aspects concerning this study.

\subsection{Work-Related Qualities in IT}

Obtaining a degree does not necessarily guarantee success in real life. Friedman (2014, no page) reports on an interview with Bock (senior vice-president of people operations for Google). According to Bock, "Too many colleges ... don't deliver on what they promise. You generate a ton of debt, you don't learn the most useful things for your life." Bock shared five criteria that Google uses when evaluating job candidates, namely integrative cognitive ability (pull together unrelated bits of information, "it's not I.Q."); emergent leadership (lead and sometimes let someone else lead); intellectual humility ("step back and embrace the better ideas of others"); ownership (responsibility and ownership, solving problems collaboratively); and expertise (e.g. coding ability). Bock reveals that the first four are the main qualities required for Google employees. According to the Association for Computing Machinery and IEEE Computer Society (ACM/IEEE) (Sahami, Danyluk, Fincher, Fisher, Grossman, Hawthorne \& Cuadros-Vargas, 2013) essential characteristics of IT graduates include that they need to be able to: analyse a problem; design, implement and evaluate a program; function effectively in teams; understand professional and social issues and responsibilities; apply skills, tools and practices; integrate IT-based solutions effectively into the user environment; understand and apply best practices; and assist in the creation of an effective project plan. Such characteristics are also associated with computational thinking and participation.

\subsection{Computational Thinking and Participation}

Computational thinking relates to problem solving, system development and an understanding of the human way of life with regard to fundamental concepts in Computer Science (Kafai, 2016; Wing, 2006). Wing (2006:33-35) is of the opinion that "Computer Science inherently draws on engineering thinking, given that we build systems that interact with the real world ... solve problems, manage our daily lives, and communicate and interact with other people." Computational participation involves creating a tangible artefact that can be shared with others as Kafai (2016:27) asserts, "Coding was once a solitary, tool-based activity. Now it is becoming a shared social practice." Thus, to learn how to code, students need to learn computer science fundamentals as well as to participate in sharing their work with one another. Computational thinking and participation may be addressed by using various teaching-learning strategies.

\subsection{Problem-Based Projects}

Problem-based learning (PBL) is a pedagogy that is based on authentic learning, it is student-centred, collaborative and requires reflective learning (Da Silva, Kruta de Araújo Bispo, Rodriguez \& Vasquez, 2018). Students are challenged with the problem of inquiry whereas the lecturer serves as the facilitator. According to Bagheri, Ali, Abdullah, and Daud (2013), PBL has the ability to enhance students' SDL and real-life experiences in a specific field. Essential features of PBL involve the following (Savery, 2015): it is an approach where students are actively involved, team members work together to solve fuzzy problems, students take responsibility and ownership of their learning processes, problem scenarios require integrated knowledge and skills, and team cooperation is essential. Distinctive team cooperation, critical thinking, innovative construction of an artefact, as well as self- and peer group assessment are of particular importance in PBL (Havenga, 2015). Chorfi, Hedjazib, Aouaga and Boubicheb (2020) highlight that the combination of PBL and teamwork enhance responsible learning as well as the development of essential problem solving and programming skills for a changing society. Moreover, Sarkar, Overton, Thompson and Rayner (2020) concur that the development of such qualities are highly valued by employers. In this research, PBL was structured around the development of a project. 


\subsection{Real-Life Skills and Self-Directed Learning}

It is essential that students develop real-life skills to cope with future demands since continuous changes are inherently characteristic of career trajectories (Beagon \& Niall, 2015; Borgen \& Hiebert, 2014). As a result, higher education needs to prepare students for employability, skill development and future careers. Learning capabilities should accordingly be occupied with real-life experiences to contribute towards the needs of society. The NWU's Teaching and Learning Strategy defines desired graduate attributes in relation to six domains. One of the domains is "Innovative, critical thinkers" which entails "The ability to solve complex and unfamiliar problems through the discovery and creation of new knowledge and understanding". Another domain is listed as "self-directed and lifelong learners, who are able to work independently, utilise resources effectively, and exercise initiative" (NWU, 2016:12,13). SDL is a process towards independent and responsible learning where goals are explicitly formulated, appropriate strategies are implemented, and reflective activities are used to direct an individual's learning (Knowles, 1975). Students need to engage in their learning, transfer their knowledge to new situations and take ownership of their learning processes. Personal attributes of self-direction involve responsible and strategic abilities, perseverance, autonomous learning and the ability to challenge real-world problems (Merriam, Caffarella \& Baumgartner, 2007).

\subsection{Information Security Course}

'Information security' refers to strategies involved to protect confidential, private and sensitive data, information and systems from unauthorised access, (mis)use, destruction, modification or disruption (Pfleeger, Pfleeger \& Margulies, 2015). The Information Security course aims to provide students with insight into the weaknesses of computerised environments and encryption and decryption techniques among others. As part of this course, students need to investigate the following three encryption algorithms.

The Vigenere algorithm is a poly-alphabetic substitution cipher (Whitman \& Mattord, 2016). A table with the $26 \times 26$ alphabet letters is used for encrypting and decrypting messages by permuting all letters with all the others (e.g. A could become an a, b, c ... z). A keyword is chosen, which is combined with the plain text and repeated over the length of the plain text (Pfleeger \& Pfleeger, 2007).

In the Vernam cipher, a long sequence of numbers is used in combination with the plain text to provide a strong cipher. A plain text is combined with the long non-repeating key (random numbers). The cryptogram is the sum mod 26 (alphabet of 26 letters) of each coded letter ('mod' is the remainder after division).

The aim of using the Columnar transposition algorithm is to get diffusion of the plain text characters by spreading them over the whole length of the message to be encrypted. The message is written row by row in a fixed column size. This is followed by reading the message back column by column, getting the resultant cryptogram (Pfleeger \& Pfleeger, 2007). For example, the words ENCRYPT is presented as follows: EY NP $\mathrm{CT} \mathrm{R}^{*}$ (by reading the text column by column). Variations can be carried out to get improved diffusion, or the columns can be rearranged in order to enhance the complexity of the cipher.

\begin{tabular}{|c|c|c|c|}
\multicolumn{1}{c}{1} & \multicolumn{1}{c}{2} & \multicolumn{1}{c}{3} & \multicolumn{1}{c|}{4} \\
\hline $\mathrm{E}$ & $\mathrm{N}$ & $\mathrm{C}$ & $\mathrm{R}$ \\
\hline $\mathrm{Y}$ & $\mathrm{P}$ & $\mathrm{T}$ & $*$ \\
\hline
\end{tabular}

Figure 1. Message displayed using the columnar transposition algorithm

The research questions were the following:

1) How can problem-based projects support students to implement different cryptography algorithms?

2) How can problem-based projects enhance students' self-directed learning in the Information Security course? 


\section{EMPIRICAL RESEARCH}

\subsection{Research Approach and Methodology}

Research was done from the social-constructivist point of view where reality is constructed by students working in collaboration and challenging each other's perspectives. A qualitative methodology was followed.

\subsection{Study Context}

The cohort of honours students in the Information Security course involved 21 students (68\% of all the honours students selected this course). The study was approved by the ethical committee of the university. In the Information Security course, students are required to participate in seminars, submit assignments, search for appropriate information, present their project to the class, and write tests as well as an examination. It is also expected of the students to work in groups, explore solutions and take control of their own learning processes. Honours students need to solve security-related problems and recommend measures to address and counteract these. Two students worked in a group and selected the peers themselves. Members were required to develop a program to manage the encryption and decryption of messages and files (Table 1). Each team had to develop one program involving four different algorithms (Vigenere, Vernam, Columnar transposition) as well as an own choice cipher. A graphical interface was developed to demonstrate the algorithms. Students worked after class time and were allowed to use any programming platform (Drevin, 2016). They compiled a concise report comprising a table of contents, introduction, aims, topic selected, summary and conclusion as well as a complete reference list. All programs had to install from a CD during demonstration. Formative assessment included individual as well as group assignments that covered creativity, application of knowledge, scientific communication and reporting. Summative assessment comprised the project, the scientific report as well as the final examination. Prior to project submission, students received a rubric regarding: the time schedule, weekly project sheets, group reflection, software project and report, team presentation as well as group assessment. A final score out of 100 was assigned to each project.

Table 1 . The research design in this study

\begin{tabular}{|c|c|}
\hline $\begin{array}{l}\text { Activities prior to the } \\
\text { intervention (individual) }\end{array}$ & $\begin{array}{c}\text { Intervention (10 weeks) } \\
\text { (team completion) }\end{array}$ \\
\hline $\begin{array}{l}\text { Completion of questions: } \\
\text { 1) information security } \\
\text { knowledge; and } \\
\text { 2) PBL (understanding of } \\
\text { and previous experiences } \\
\text { with PBL) }\end{array}$ & $\begin{array}{l}\text { Plan the project and complete a time schedule } \\
\text { Submit weekly project sheets (responsibilities and progress). Develop a } \\
\text { project that implements different cryptographic algorithms and a } \\
\text { project report as deliverables. Obtain students' reflections regarding } \\
\text { their responsibilities and experiences with problem-based projects }\end{array}$ \\
\hline
\end{tabular}

\subsection{Data Collection and Analysis}

Qualitative data collection prior to the intervention involved completion of open-ended questions regarding students' knowledge about information security as well as their initial experiences about PBL (Table 1). This was followed by gathering the teams' weekly project sheets and narrative reflections regarding their project work. Students feedback were analysed according to abilities such as responsibility in learning, ownership, perseverance, active and autonomous learning, cooperation and the ability to solve challenging problems. In the weekly project sheets students had to respond to the following:

Give feedback regarding the assistance and support among your team members

Give feedback regarding your team's personal interaction and communication

Give feedback on the extent to which you as a group have achieved your goals

Which problems or challenges did your team experience in not achieving your goals?

Explain how your team has solved or managed the problems or challenges mentioned above

Reflect on the pace of your team's progress in project development.

Specify which information you searched for regarding the development of your project. List all resources 
Give yourself and your teammates a mark allocation in relation to your contribution to the project, with motivation.

The data were manually coded. Both concept coding (broader meaning) and descriptive coding (labelling a word or phrase) were used to identify certain patterns of meaning as the outcome of the coding and categorisation of data. Differences among the groups and re-occurring themes and concepts were identified and agreed upon by the researchers.

\section{RESULTS AND DISCUSSION}

\subsection{Results}

The following themes were identified: Theme 1: Experiences concerning PBL (prior to the intervention), Theme 2: Team obligations, Theme 3: Participants' challenges and reflections, and Theme 4: Knowledge and skills obtained regarding information security. All quotations are reflected verbatim and unedited.

\subsubsection{Experiences Concerning PBL}

Students mentioned that working on a project was an impetus for learning, which enabled a deeper understanding and programming of distinct ciphers. Some examples were the following: "Learning while applying knowledge in a practical manner, asking a project as a catalyst for learning" (Participant 11 (P11)). "Study through practical and visible experience instead of sitting in class and given limited knowledge" (P13, P18). "Applying various or new techniques as part of a project to fully understand a specific subject domain. I like this" (P19). "Consequently to obtain a deeper and better understanding of the topic" (P20). "Being given a project that requires self-learning and self-motivation in order to learn and overcome a problem that has not been physically taught to us" (P21). "Though the project took a lot of effort hour, it was fascinating and has enlightened us about the complications of working on a real-life/deployable project and made us to understand why it takes software companies lot of time to deliver a stable version of software products" (P14). One student was not sure what PBL entailed and mentioned, "Not 100\% sure. Learn by doing. Not passive" (P17).

\subsubsection{Team Obligations}

Examples of teamwork, interaction and management of collaborative activities involved meetings, essential group discussions as well as assistance and support to one another. "Each team member was allocated an algorithm to research on ... The team had a progress status meeting ... Ensure that everyone on the team is on the same page with the project expectations" (P13). "The support is great and they are always eager to give assistance when certain requirements ... are not clear" (P13). Students discussed ways to enhance their understanding: "Team members again discussed the programming of the Vernam and Vigenere to enable that both understand and do the programming" (P2). However, members experienced challenges with the columnar transposition algorithm: "Research was again reviewed and different aspects was explained by different members to support the ... programming of the algorithm for Columnar Transposition ... All the previous work was debugged and tested" (P19).

\subsubsection{Participants' Challenges and Reflections}

Some challenges entailed problems with the format of documentation, decisions regarding an appropriate programming language and time concerns: "As the format of documentation differs between the team members, the integration of algorithms also differs since members make use of different user interfaces. After hard work we achieved our aims" (P1). "It was challenging to decide on the programming language ... which language will execute the work accurately [as] expected ... the coding process took longer than expected. However, the team managed to get all work completed on time" (P13). Programming of the fourth algorithm challenged students: "We experienced problems to decide on how to efficiently program the fourth algorithm ... found new ways to solve the programming problems" (P2). Moreover, time concerns involved: "There was an enormous time shortage issue ... it takes software companies a lot of time to deliver a stable version of software products ... we devised a time schedule to guide the project, rethink our approach, adjusted our personal schedules" (P19). "The first three phases went as planned but ... development and testing was rigorous ... to ensure that the program works" (P14). 


\subsubsection{Knowledge and Skills Obtained Regarding Information Security}

Students obtained knowledge and programming skills regarding the different algorithms: "Check which languages support the Vigenere algorithm ... The team was able to be on schedule and deliver [the] expected outcome" (P13). "Obtain the appropriate background knowledge ... involving different encryption algorithms and to decide which of them to include or combine with others to use as the extra one for the project" (P19). Participating students persisted in solving the four encryption algorithms: "The accumulated knowledge about the different encryption algorithms cannot be taken away ... therefore we can say that it is bug free to some degree, and fully functional to do what it is intended to do" (P19). "We as a team have achieved our goal of completing all four algorithms at this stage and combining all into one program, as well as starting off with the final documentation" (P20).

\subsection{Discussion}

This section answers both the research questions. The first research question was: How can problem-based projects support students to implement different cryptography algorithms?

Problem-based projects (PBP) enable students to apply new techniques to enhance a deeper and better understanding of Information Security. Theme 1 outlined some views and experiences regarding the learning in problem-based contexts: "A project as a catalyst for learning" (P11). "Practical and visible experience" (P13, P18). "Learn by doing" (P17). Project development requires self-learning and self-motivation: "In order to learn and overcome a problem that has not been physically taught to us" (P21). "It ... has enlightened us about the complications of working on a real-life project and ... why it takes software companies lot of time to deliver a stable version of software products" (P14). Applying PBP provided opportunities for the development of skills and enabled students to elaborate on their knowledge (Theme 4). Students obtained background knowledge, different approaches to the algorithms and the programming thereof (P19), and they checked which languages were better suited to implement the Vigenere algorithm (P13). Initially, students experienced some problems with the decryption of the columnar transposition algorithm (P1, P19). Nevertheless, Participant 1 (P1) decided to program the fourth algorithm efficiently and found new ways to solve the problems, whereas another team searched for a programming language which could execute the program "accurately as expected" (P13) (Theme 3).

Some members ensured that the program worked by applying rigorous testing of their programs (P14). The knowledge obtained about the encryption algorithms is clearly outlined by P19 as he stipulated, "the accumulated knowledge about the different encryption algorithms cannot be taken away ... applying various or new techniques as part of a project to fully understand a specific subject domain. I like this." Emerging from these examples is the use of PBP as a catalyst for learning by doing. Students were required to figure out what the problem entailed and explored possible solutions, e.g. the columnar transposition algorithm had not been taught to them previously - only the mechanism was explained. Consequently, the emphasis was on the process of solving the problem rather than on merely finding a solution. The importance of knowledge and skill development in real-life contexts was also revealed by Friedman (2014), Kafai (2016) and Wing (2006). Results underscore the view that PBP are problem-focused and student-centred and integrate IT-based solutions into the user environment (Sahami et al., 2013). Similar studies also found that PBL enabled students to practice and develop skills, such as ownership and management of the project, as well as to generate solutions that could not be done as part of general coursework (McManus \& Costello, 2019). They also noted that individual responsibility and accountability enforced time management skills.

The second research question was: how can problem-based projects enhance students' self-directed learning in the Information Security course? Participants mentioned their responsibility as individuals and as a group (Theme 2). Each team member was allocated an algorithm on which to do research, and participants had meetings to indicate their progress, they gave assistance and supported one another (P13), and reviewed and explained some aspects (P19). Since the teams where small (comprising mostly two members), members were required to establish goals, share responsibilities and be accountable for group tasks. Assisting each other (P13, P19) and balancing challenges enhanced opportunities for developing interdependence and SDL.

Debugging and testing of programs were also part of group responsibilities as mentioned by P19. Participants strengthened one another's understanding of encryption algorithms (P2). Group members therefore owned a project and they were responsible for all aspects of the encryption project. Ownership is also outlined by Friedman (2014) as one of the important criteria that Google uses when evaluating job 
candidates. Sahami et al. (2013) further elaborate that students need to understand social issues and responsibilities.

Participating students mentioned some challenges as outlined in Theme 3. They experienced technical problems, such as the format of the document, and the integration of algorithms, which was problematic as a result of using different user interfaces (P1). A main concern was time constraints, as the coding process took longer than expected. P19 also noted, "There was an enormous time shortage issue." Time constrains are of importance to ensure successful delivery. Some students managed their time challenges by rethinking their approach, and they adjusted their personal schedules accordingly (P19, P13). Management of own time, persistence in learning and viewing problems as challenges, are characteristics of highly self-directed learners as emphasised by Merriam et al. (2007). As a result, problem-based projects served as an appropriate method to enhance students' SDL and real-life experiences in an Information Security course. Figure 2 displays a proposed integrated model for SDL skill development in a PBL context.

The model in Figure 2 is based on the integrated findings in this study. PBP provided opportunities for knowledge, skill development and collaboration to foster students' SDL where they needed to solve real-life problems in new ways. The model comprises three main entities, namely collective responsibility and ownership, collaborative knowledge construction and real-life experiences, on the outside of the triangle. These entities were also mentioned in the literature overview for example, collective responsibility and ownership (intellectual humility and ownership - Friedman, 2014), collaborative knowledge construction (integrative cognitive ability - Friedman, 2014), and real-life experiences (develop real-life skills to cope with future demands - Beagon \& Niall (2015); Borgen \& Hiebert (2014)). Associations, presented as verbs, indicate the dynamicity between two entities. For example, the collective responsibility and ownership entity contributes toward collaborative knowledge construction (especially in a cooperative team). Likewise, collaborative knowledge construction may contribute towards collective responsibility and ownership (thus indicated in Figure 2 with bi-directional arrows). Similarly, collective responsibility and ownership and real-life experiences enhance one another whereas collaborative knowledge construction develops real-life experiences. In the same way, real-life experiences may provide for the development of collaborative knowledge construction where team members solve a complex problem. Selected exemplars are presented within the triangle. For example, achieve team goals ("After hard work we achieved our aims" [P1]), solve real-life problems in new ways ("found new ways to solve the programming problems" [P2]), and apply new techniques ("Learning while applying knowledge in a practical manner, asking a project as a catalyst for learning" [P11]). The attributes mentioned here are part of SDL as Knowles (1975) emphasises independent, responsible learning, the use of strategies and reflective activities to direct the learning process.

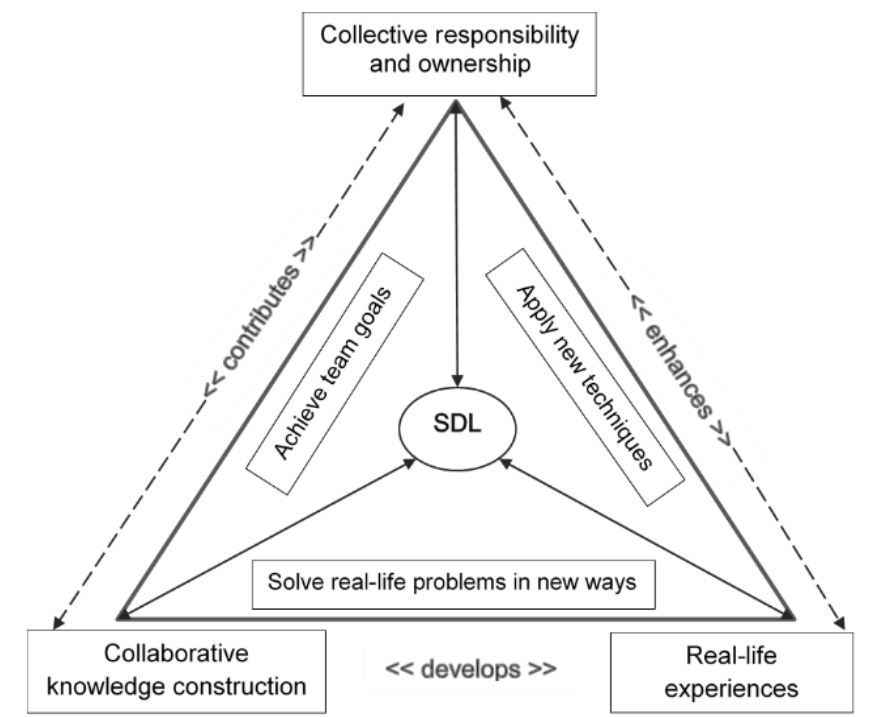

Figure 2. A proposed integrated model for SDL skill development in a problem-based context 


\section{CONCLUSION}

This research explored the application of problem-based projects to enhance honours students' SDL in an Information Security course where cryptography algorithms had to be planned and implemented. PBP supported participants to apply new techniques, increase their knowledge and develop real-life skills. Although it emerged that students initially experienced some challenges, the use of the cryptography project resulted in the improvement of students' SDL. Participants enhanced their knowledge and technical experience, and developed employability skills. Therefore, synergy between theoretical knowledge and practical programming experiences should be emphasised in problem-based projects as a reflection of real-world IT settings. Moreover, a model for SDL skill development has been proposed in a PBL context as a way to integrate responsible learning and ownership, collaborative knowledge construction and the experience of real-world settings, as these are beneficial for the IT profession.

For future work, teaching practices, such as problem-based projects, could be applied in various Computer Science courses to enable students addressing real-world problems while working in small group settings. Some limitations of this research were that the class size was small and generalisations cannot be made, although good insight into the project experiences of these students was obtained. In addition, the emerged model needs to be evaluated in computer science contexts.

\section{REFERENCES}

Bagheri, M., Ali, W.Z.W., Abdullah, M.C.B. \& Daud, S.M. 2013. Effects of project-based learning strategy on self-directed learning skills of educational technology students. Contemporary Educational Technology, 4(1):15-29.

Beagon, U. \& Niall, D. 2015. Using problem based learning to develop graduate attributes in first year engineering students. [Online]. Available: https://arrow.dit.ie/engschcivcon/92/ [Viewed 04 January 2019].

Borgen, W. \& Hiebert, B. 2014. Orienting educators to contemporary ideas for career counselling: An illustrative example. In Handbook of career development, international and cultural psychology. Edited by G. Arulmani, A.J. Bakshi, F.T.L. Leong \& T. Watts. NY:Springer-Verlag, pp. 1-771.

Chorfi, A., Hedjazi, D., Aouag, S. \& Boubiche, D. 2020. Problem-based collaborative learning groupware to improve computer programming skills. Behaviour \& Information Technology. [Online]. Available: https://scholar.google.com/scholar?hl=en\&as_sdt=0\%2C5\&q=Problem-

based+collaborative+learning+groupware+to+improve+computer+programming+skills+Atef+Chorfi\&btnG= [Viewed 26 October 2020]

Da Silva, A.B., Kruta de Araújo Bispo, A.C., Rodriguez, D.G. \& Vasquez, F.L.F. 2018. Problem-based learning: A proposal for structuring PBL and its implications for learning among students in an undergraduate management degree program. Revista de Gestão, 25(2):160-177.

Drevin, L. 2016. ITRI 615 PEC Computer Security 1. Study guide, Potchefstroom campus, Northwest-University. Ivyline Technologies.

Friedman, T.L. 2014. How to get a job at Google. The New York Times. [Online]. Available: https://www.nytimes.com/2014/02/23/opinion/sunday/friedman-how-to-get-a-job-at-google.html?_r=0 [Viewed 10 March 2017].

Havenga, H.M. 2015. Project-based learning in higher education: exploring programming students' development towards self-directedness. South African Journal of Higher Education, 29(4):135-157.

Kafai, Y.B. 2016. From computational thinking to computational participation in K-12 education. Communications of the ACM, 59(8):26-27.

Knowles, M.S. 1975. Self-directed learning: A guide for learners and teachers. New York, NY: Association Press.

McManus, J.W. \& Costello, P.J. 2019. Project based learning in computer science: a student and research advisor's perspective. Journal of Computing Sciences in Colleges, 34(3):38-46.

Merriam, S., Caffarella, R. \& Baumgartner, L. 2007. Learning in adulthood. $3^{\text {rd }}$ ed. San Francisco, CA: Jossey-Bass.

Mohd-Yusof, K. 2017. Sustaining change for PBL at the course level. In PBL in engineering education. International perspectives on curriculum change. Edited by A. Guerra, R. Ulseth \& A. Kolmos. Rotterdam: Sense, pp. 13-32.

NWU (North-West University). 2016. North-West University. Teaching and learning strategy: 2016-2020. Potchefstroom. [Online]. Available: http://www.nwu.ac.za/sites/www.nwu.ac.za/files/files/i-governancemanagement/documents/2017.NWU.TeachingLearningStrategy.pdf [Viewed 04 January 2019].

Pfleeger, C.P. \& Pfleeger, S.L. 2007. Security in computing. Upper Saddle River, NJ: Prentice Hall. 
Pfleeger, C.P., Pfleeger, S.L. \& Margulies, J. 2015. Security in computing. $5^{\text {th }}$ ed. Upper Saddle River, NJ: Prentice Hall.

Sahami, M., Danyluk, A., Fincher, S., Fisher, K., Grossman, D., Hawthorne, E., \& Cuadros-Vargas, E. 2013. Computer Science Curricula 2013: Curriculum guidelines for undergraduate degree programs in Computer Science. Association for Computing Machinery \& The Institute of Electrical and Electronics Engineers Computer Society. doi: $10.1145 / 2534860$

Sarkar, M., Overton, T., Thompson, C.D. \& Rayner, G. 2020. Academics' perspectives of the teaching and development of generic employability skills in science curricula. Higher Education Research \& Development, 39(2):346-361.

Savery, J.R. 2015. Overview of Problem-Based Learning: Definitions and Distinctions. In: Walker, A., Leary, H., Hmelo-Silver, C.E. and Ertmer, P.A. (Eds), Essential Readings in Problem-based Learning. Exploring and Extending the Legacy of Howard S. Barrows. Indiana: Purdue University Press.

Taylor, E. \& Goede, R. 2012. Computer science students, learning styles and readiness for self-directed learning. In Proceedings of the ISTE International Conference on Mathematics, Science and Technology Education. Pretoria: UNISA Press, pp. 291-300.

Ulseth, R. \& Guerra, A. 2017. Introduction. PBL in Engineering Education. International Perspectives on Curriculum Change. In PBL in engineering education. International perspectives on curriculum change. Edited by A. Guerra, R. Ulseth \& A. Kolmos. Rotterdam: Sense. pp. vii-x.

United Nations Educational, Scientific and Cultural Organization. 2015. The role of higher education in promoting lifelong learning. Hamburg: UNESCO Institute for Lifelong Learning.

Whitman, M.E. \& Mattord, H.J. 2016. Principles of information security. Boston, MA: Cengage Learning.

Wing, J.M. 2006. Computational thinking. Communications of the ACM, 46(3):33-35. 